Chapman University

Chapman University Digital Commons

Physical Therapy Faculty Articles and Research

Physical Therapy

$1-16-2015$

\title{
Clinical Assessment of the Infant and Child Following Perinatal Brachial Plexus Injury
}

Susan V.Duff

Carol DeMatteo

Follow this and additional works at: https://digitalcommons.chapman.edu/pt_articles

Part of the Musculoskeletal System Commons, Nervous System Commons, Other Rehabilitation and Therapy Commons, Pediatrics Commons, Physical Therapy Commons, and the Physiotherapy Commons 


\section{Clinical Assessment of the Infant and Child Following Perinatal Brachial Plexus Injury}

\section{Comments}

NOTICE: this is the author's version of a work that was accepted for publication in Journal of Hand Therapy. Changes resulting from the publishing process, such as peer review, editing, corrections, structural formatting, and other quality control mechanisms may not be reflected in this document. Changes may have been made to this work since it was submitted for publication. A definitive version was subsequently published in Journal of Hand Therapy, volume 28, issue 2, in 2015. DOI: 10.1016/j.jht.2015.01.001

The Creative Commons license below applies only to this version of the article.

\section{Creative Commons License}

\section{(c) 1 (1) 90}

This work is licensed under a Creative Commons Attribution-Noncommercial-No Derivative Works 4.0 License.

\section{Copyright}

Elsevier 
J Hand Ther. 2015 ; 28(2): 126-134. doi:10.1016/j.jht.2015.01.001.

\title{
Clinical Assessment of the Infant and Child Following Perinatal Brachial Plexus Injury
}

\author{
Susan V. Duff, EdD, PT, OTR/L, $\mathrm{CHT}^{\mathrm{a}}$ [Associate Professor] and Carol DeMatteo, MSc, Dip \\ $P \&$ OT $^{\mathrm{b}}$ [Associate Professor] \\ aThomas Jefferson University, Department of Physical Therapy, 901 Walnut St., Suite 510, \\ Philadelphia, PA 19107, susan.duff@jefferson.edu \\ bMcMaster University, School of Rehabilitation Science, 1400 Main St West, Hamilton, Ontario, \\ Canada, L8S 1C7, dematteo@mcmaster.ca
}

\begin{abstract}
STUDY DESIGN—Literature review

INTRODUCTION-After perinatal brachial plexus injury (PBPI), clinicians play an important role in injury classification as well as the assessment of recovery and secondary conditions. Early assessment guides the initial plan of care and influences follow-up and long-term outcome.
\end{abstract}

PURPOSE-To review methods used to assess, classify and monitor the extent and influence of PBPI with an emphasis on guidelines for clinicians.

METHODS-We use The International Classification of Functioning, Disability, and Health $(I C F)$ model to provide a guide to assessment after PBPI for rehabilitation clinicians.

DISCUSSION-With information gained from targeted assessments, clinicians can design interventions to increase the opportunities infants and children have for optimal recovery and to attain skills that allow participation in areas of interest.

\section{Keywords}

brachial plexus injury; infant; child; assessment; muscle; weakness; international classification of functioning; disability; health

\section{Introduction}

The purpose of this paper is to review methods to assess and classify perinatal brachial plexus injury (PBPI) in infants and children with an emphasis on guidelines for clinicians. PBPI which occurs primarily during the birth process can be transitory or have long-term consequences. ${ }^{1}$ The incidence of PBPI reportedly ranges from 0.38 to 4.6 per 1000 live

\footnotetext{
(C) 2015 Published by Hanley Belfus, an imprint of Elsevier Inc.
}

Publisher's Disclaimer: This is a PDF file of an unedited manuscript that has been accepted for publication. As a service to our customers we are providing this early version of the manuscript. The manuscript will undergo copyediting, typesetting, and review of the resulting proof before it is published in its final citable form. Please note that during the production process errors may be discovered which could affect the content, and all legal disclaimers that apply to the journal pertain. 
births depending on mean birthweight and obstetrical care in the region. ${ }^{1-4}$ The most frequent cause of PBPI is a unilateral traction injury due to catching of the anterior or posterior shoulder behind the symphysis pubis or sacrum of the mother. ${ }^{5-8}$ This is referred to as shoulder dystocia. Other risk factors for PBPI include maternal gestational diabetes, prolonged labor, labor induction, mechanical assistance (vacuum, forceps) or infant size > $90^{\text {th }}$ percentile (4500 to $5000 \mathrm{~g}$ ). ${ }^{9-10}$ Despite the known risk factors, the positive predictive values for identifying PBPI prior to birth are less than $15 \% .{ }^{11}$ Risk factors continue to be investigated with the goal of prevention. ${ }^{12-13}$

The recovery rate from PBPI is now estimated to be closer to $65 \%{ }^{14-17}$ versus previous reports of $90 \% 18$. The difference in rate is influenced by the definition of complete recovery, the scale or method used to measure recovery and the age of the child. Incomplete recovery is more apparent in older children as daily upper limb tasks increase and become more complex.

Clinicians have an important role in injury classification as well as the assessment of recovery and secondary conditions. Early assessment guides the initial plan of care and influences follow-up and long-term outcome.

\section{Models of Rehabilitation}

Clinicians use theoretical models to guide the choice of assessment and intervention and to conceptualize outcomes. The traditional medical model concentrates on curing disease with physical impairment as the main focus. The International Classification of Functioning, Disability and Health (ICF) developed by the World Health Organization (WHO, see Fig. 1). ${ }^{19}$ is a more contemporary model used by rehabilitation clinicians. This model relies on the dynamic interaction of multiple subsystems in which environmental factors play a key role. Each level of the ICF framework is relevant at all ages yet, the treatment priorities after PBPI typically shift from a strong emphasis on body, structure and function in infancy toward greater emphasis on activity and participation as the child gets older (see Table 1).

The ICF can assist the clinician with decisions on measurement including what, when and which measurement tool to choose. Table 2 and 3 provide a sample list of outcome measures (with abbreviations) classified within the ICF. Table 2 a lists assessment tools that are validated for this population (Table $2 \mathrm{a}$ ). Table $2 \mathrm{~b}$ includes standardized assessments that are potentially useful but currently are not validated for use after PBPI. These tables are guidelines in the choice of assessment for infants and children with PBPI.

\section{Assessment: Infant}

Early infancy is the time to focus on impairment (Table 1). During this period, the team determines the extent of the injury and monitors recovery. Early monitoring informs the decision regarding the need for reconstructive nerve surgery. Select medical tests such as electrodiagnostic measures, MRI, and ultrasound are often used to verify clinical findings. 


\section{History}

Key information to gather from medical records and parents/caregivers includes a history of maternal gestational diabetes, incidence of sibling PBPI, length of maternal labor and mechanical assistance at delivery. Additional information to document includes the incidence of birth hypoxia, infant APGAR scores, infant birthweight, clavicular fracture and the appearance, posture and movement in the affected limb post-birth. If the history is obtained weeks to months after birth specifics regarding the progression and quality of affected limb movement can be obtained. Details of the actual birth and birthing experience are also important to explore with parents. For many it has been a traumatic experience which they may have not resolved emotionally ${ }^{85}$ and can ultimately affect their ability to respond to the needs of their infant.

\section{Observation}

An initial observation of the infant's state, ${ }^{66}$ parent-infant interaction, ${ }^{86}$ infant posture ${ }^{52}$ and general sensorimotor behavior ${ }^{23}$ should be conducted as all of these will greatly affect the formal assessment and intervention. An infant who is highly irritable or a parent who is fearful of the affected limb may influence testing priorities and techniques. Resting posture and spontaneous movements observed in the neonatal period after PBPI provide a general indication of the extent of the injury, muscular involvement and the presence of pain. Global motor asymmetries, not just in the upper limb, affect the development of postural control and long-term function and should be observed and monitored as they may be indicative of central neurological issues. ${ }^{52,87-88}$

After partial or full denervation, the affected upper limb often lies immobile in postures that provide evidence of the lesion. For example, the common "waiter's tip" position of shoulder internal rotation/adduction, elbow extension, supination and wrist flexion suggests injury to the C5-C6 (C7) spinal nerves or roots with partial or full denervation in the associated muscle groups. ${ }^{2}$ Some infants maintain the head turned away from the affected side, which may be indicative of injury to neck musculature (i.e., scalenes or sternocleidomastoid), the presence of regional nerve pain or sensory neglect. Sustained asymmetrical head posturing places an infant with PBPI at-risk for torticollis, ${ }^{89-90}$ and/or secondary plagiocephally. ${ }^{89-90}$

Specific signs and symptoms are indicative of extensive nerve involvement. The presence of ptosis (drooping eyelid), miosis (pupil constriction) and/or anhidrosis (dry eye) are signs of unilateral Horner's syndrome or injury to the sympathetic trunk; which is linked to injury in the lower roots of the brachial plexus. ${ }^{91}$ Difficulty with oxygenation, feeding and asymmetric chest expansion are symptoms of partial denervation to the diaphragm and warrant further screening for phrenic nerve injury (nerves $\mathrm{C} 3, \mathrm{C} 4$, and C5). ${ }^{92}$ Concerns raised during observations require further assessment.

\section{Objective Testing}

Assumptions made during an observation can be confirmed or refuted through the use of objective measurements. Table 2 a provides a list of objective measures within the ICF framework validated for infants and children with PBPI. Table $2 b$ lists measures that are currently not validated with this population but have potential for use. 
Pain-If the infant grimaces upon light palpation of the neck and upper shoulder region pain is suspected. If sustained head posturing is noted during observation, a test of visual tracking provides information on the influence pain has on neck movement and visual scanning. The Face, Legs, Activity, Cry, Consolability (FLACC) scale can be used to objectively rate pain on a $0-10$ scale based on behavioral cues from 5 categories (Table 4). ${ }^{53}$ Many hospitals have adopted the FLACC scale to objectively measure pain in all infants.

Classification of Injury-The original classification of PBPI by Narakas ${ }^{30}$ was modified by Al-Qattan ${ }^{31}$ to reflect neural recovery over the first few months. This combined scale is useful as an early assessment tool (see Table 5). Once a preliminary diagnosis is made, the infant and family should be referred to a center which specializes in PBPI. A team including a physical or occupational therapist and a surgeon skilled in nerve reconstructive techniques is optimal to guide the plan of care. Ideally, a referral is made within one month of injury to allow for prevention of contractures and deformity, early assessment, monitoring of recovery and initiation of intervention with support and education for families. If distance from care is a factor, it is possible to implement a telemedicine program ${ }^{93}$ to support a combined plan of care with the local medical/therapy team and the specialty center.

Neurological and Physical Assessment-Since neurologic disorders can ensue secondary to hypoxia experienced during birth, a neurological screen ${ }^{23}$ is essential. This can include an assessment of muscle tone and primitive reflexes and other components such as spontaneous movement ${ }^{68}$ and sensation ${ }^{55}$ (reviewed below). Findings from an examination of deep tendon reflexes ${ }^{23}$ can provide information on muscle innervation and integrity. Physical palpation for clavicular and humeral fractures should be done and confirmed with $\mathrm{x}$-ray. ${ }^{27} \mathrm{~A}$ radial nerve injury is suspected is there is wrist drop into flexion, visible ecchymosis and/or a palpable nodule (suggestive of subcutaneous fat necrosis) along the posterolateral upper arm ${ }^{94-95}$ Palpation of the skull can confirm or refute the presence of a cephalo-hematoma ${ }^{96}$ or plagiocephally ${ }^{90}$.

Passive Range-of-Motion-Assessment of PROM available at the neck, glenohumeral $(\mathrm{GH})$ and scapulothoracic (ST) joints is essential. ${ }^{29,89}$ Passive ROM into lateral neck flexion and cervical rotation is assessed if postural asymmetries are suggestive of a torticollis. ${ }^{89}$ Ideally, the GH joint is evaluated with the scapula stabilized during elevation (flexion/ abduction), external rotation (ER) and horizontal adduction. During elevation and horizontal adduction the scapula is stabilized laterally to prevent upward rotation or abduction (Fig. 2a). During shoulder ER, medial glide and elevation of the scapula are prevented (Fig. 2b-c) while the GH joint is externally rotated from an adducted position. Ongoing assessment of PROM throughout infancy and childhood is recommended due to the risk for contracture. ${ }^{29}$

Motor Assessment-An assessment of spontaneous arm movement in supine, prone, sidelying and supported sitting with or without provocation provides information on available motion. According to Bouwstra et al., 67 "spontaneous movements are endogenously generated by the central nervous system during fetal life and early infancy". An assessment of generalized movements (GMs) ${ }^{97}$ predicts infants at-risk for neurological dysfunction. ${ }^{97-98}$ Buitenhuis et al. ${ }^{68}$ found a diminished quality of fidgety GMs at 3 months 
of age in infants who sustained PBPI. While GM's could be valuable to screen for neurological dysfunction and arm asymmetry after PBPI the assessment of GM's must first be validated for use with this population. Another mode to provoke muscle activation is the elicitation of primitive reflexes and postural reactions. ${ }^{23-25}$ There are at minimum five reflexes/reactions that are quite useful with this young population since they activate muscles frequently involved post-injury (see Table 6 for details). Additional objective measures confirm or refute suspicions with regard to muscle activation.

The Active Movement Scale (AMS) ${ }^{20}$ is used to objectively examine activation of UE muscle groups. The AMS differs from the Toronto Scale (Appendix A) ${ }^{22}$ which was designed for use at 3 months of age as a predictor of outcome and use in surgical decisionmaking. The AMS was designed to be used from the neonatal period to one year of age. ${ }^{20-21}$ Yet, an advantage of the AMS is that is can be used until adolescence. ${ }^{20-21}$ Scores for fifteen UE joint motions are graded on a 0-7 point scale based on the percent of active motion observed within the available PROM. Active motions performed with gravity minimized are scored from $0-4$ and motions performed against gravity are scored from 5-7 (See Appendix B). Each of the 15 joint motions must receive a score of 4 in the gravity minimized range before a higher score against gravity can be given. The scale is proven reliable (overall $\mathrm{K}_{\mathrm{quad}}=0.89$ ). ${ }^{21}$ However, since scoring is based on active motion in the available passive range, it is recommended that PROM estimated from visual inspection be verified with goniometry. ${ }^{99}$

Sensation-Behavioral cues such as infant facial grimacing or retractive movements with active motion, PROM or tactile stimulation are used to screen sensation in the upper limb. Behavioral response to a dull pinprick or a light pinch tested along specific UE dermatomes provides objective information on sensation. The scale by Narakas ${ }^{30}$ (see Table 7) is one of the few scales to classify sensation in this population.

Electrodiagnostic Studies-Routine evaluations after PBPI do not usually include the electrodiagnostic tests of nerve conduction or invasive electromyography (EMG) due to the high probability for false negative findings in the neonatal period and false positive findings a few months post-term. ${ }^{27,38}$ van Dijk et al. ${ }^{38}$ outlined potential reasons for a discrepancy between clinical findings and EMG results. One possibility is that the small axonal size in neonates could reduce the time to complete the process of denervation and the start of reinnervation in comparison to adults. ${ }^{38}$ Aberrant re-innervation and inadequate motor $\operatorname{control}^{38}$ are other potential reasons for this discrepancy.

Despite the controversy, clinicians selectively use electrodiagnostic tests after PBPI. Needle EMG is used to examine the integrity of a muscle or muscle groups for surgical decisionmaking. Others use electrodiagnostic tests, if root avulsions are suspected. ${ }^{44}$ For example, the integrity of the roots can be assessed intraoperatively through the elicitation of motorand sensory-evoked potentials. ${ }^{43}$ As discussed above, the interpretation of EMG findings in the few months post-birth is controversial. Yet, van Dijk et al. ${ }^{40}$ found that needle EMG conducted at one month of age predicted paralysis of the elbow flexors at 3 months. Noninvasive surface EMG or biofeedback is clinically useful to determine whether muscle activation is present during skills such as reach-to-grasp behavior ${ }^{41}$ but is not used routinely. 
Further research is warranted before electrodiagnostic testing becomes routine with this population.

Radiological Assessment-Diagnostic imaging is useful early post-injury. X-ray verifies whether a clavicular or humeral fracture was sustained during delivery 27 Computerized tomography (CT)/myelography evaluates root avulsions with a sensitivity of $58.3 \%$ for post-ganglionic rupture and $72.2 \%$ for preganglionic nerve root avulsion. ${ }^{36} \mathrm{CT}$ myelograms are considered somewhat invasive since they require general anesthesia, lumbar puncture and induce radiation exposure. Magnetic Resonance Imaging (MRI) is being used more frequently as an imaging tool since it is less invasive than a CT myelogram. ${ }^{44}$ Somashekar et al. ${ }^{42}$ used MRI imaging in a small sample, to detect root avulsions at an overall sensitivity of $75 \%$ and specificity of $82 \%$. Finally, non-invasive ultrasound provides information on nerve, $\mathrm{GH}$ joint and muscle integrity thus can aide in pre-microsurgical planning. ${ }^{45-46}$ An ultrasound of the diaphragm may also be done if damage to the phrenic nerve is suspected. ${ }^{44}$ The type of imaging used is controversial and depends on the availability of the specific procedures and the preferences at each specialty center.

Developmental Testing-Muscle imbalance, postural asymmetries and diminished sensation influence sensorimotor development. Currently, there is not a developmental assessment validated for use with infants after PBPI. However, performance on an assessment standardized for use with full-term infants could be used to estimate the influence of PBPI on the achievement of motor milestones and to screen for asymmetry. Two tools are recommended. The first is the Test of Infant Motor Performance (TIMP) ${ }^{69}$ standardized for use from infants 32 weeks gestational age to $4-5$ months post-term. The original normative sample did include term infants. Thus is not intended for just preterm infants. The TIMP has been recommended in the clinical practice guidelines for torticollis. ${ }^{89}$ The Alberta Infant Motor Scale (AIMS) ${ }^{70}$ is a criterion referenced test standardized for use with infants 2 weeks post-term to 18 months of age. Other valid and reliable developmental assessments may be appropriate but require further validation for use with infants after PBPI (See Table 2b).

Psychological Factors-PBPI places the parents/caregivers and infant at risk for psychological stress. An assessment of psychological adjustment and coping strategies of parents/caregivers by the clinician is essential. ${ }^{100-101}$ An older infant or toddler could be atrisk for self-mutilation due to altered sensation in the affected limb, pain or psychological stress. ${ }^{102-103}$ Signs of injury or parental report of injury must be monitored on an ongoing basis. Referral to a psychologist or social worker for further support may be indicated.

\section{Assessment: Older Child}

As the child becomes a preschooler the focus of clinical care shifts from impairment to ageappropriate activities and participation (see Table 1). Despite the shift in priority, clinicians should continue to provide ongoing assessment of impairment, since it can limit the scope of desired activities and opportunities for social participation. 


\section{History}

During childhood information obtained on history to date including surgical and rehabilitation intervention received, guides the assessment process.

\section{Objective Testing}

Although some assessment tools from infancy are similar, additional tests reviewed below as well as those listed in Table 2, can provide more useful information for the clinician across the ICF framework as the child ages.

Motor Assessment-The AMS can be used until 15 years of age to gather information on muscle activation and joint motion. ${ }^{20-21}$ However, as the child gets older and is better able to follow verbal commands the Medical Research Council (MRC) scale ${ }^{28}$ may be more suitable to assess muscle strength. Electrodiagnostic studies reviewed above may also be a source of objective information.

The Mallet Scale ${ }^{26}$ and the Modified Mallet Scale ${ }^{27}$ (See Appendix C) are motor assessments well-suited to children 3 years of age or older. In the Modified Mallet ${ }^{27}$, the child imitates six postures that are demonstrated by the clinician for bilateral motion. Scoring ranges from $\mathrm{I}=$ no function to $\mathrm{V}=$ normal. Russo et al. ${ }^{48}$ examined the $\mathrm{GH}$ and ST joint contributions to shoulder motion based on the Modified Mallet Scale. The authors found that among children with Erb's Palsy (C5-C6 spinal root involvement) and Extended Erb's Palsy (C5-C7 spinal root involvement) the GH joint contribution was less than the ST joint in the affected shoulder primarily during global ER and elbow flexion/supination (the "hand to mouth" action). ${ }^{48}$ This supports previous work documenting atypical GH and ST joint contributions to shoulder motion in children who sustain PBPI, ${ }^{49}$ and provides further justification for use of the Modified Mallet scale ${ }^{27}$ as a motor assessment tool.

Joint and Skeletal Integrity-Measurement of joint angles via goniometry is essential, yet joint and skeletal integrity is best verified with radiological imaging. Assessment of gleno/scapular angles ${ }^{47}$ provides an objective measure of change in the relationship of the GH and ST joints from infancy to adulthood. Specific methods used to assess GH and ST joint angles are outlined in this special issue. ${ }^{47}$ Interestingly, Kozin and colleagues ${ }^{104}$ demonstrated that tendon transfers improve overall shoulder motion, but do not reduce humeral head subluxation or improve GH joint alignment. Thus, children are still at risk for joint contractures after tendon transfers warranting continued documentation of PROM and emphasis in treatment.

Measures of arm length and girth obtained as the child ages can indicate the presence of significant interlimb asymmetry. ${ }^{50-51}$ Differences in arm size and appearance are reportedly "somewhat" to "extremely" important to more than $37 \%$ of parents and families of children who sustain PBPI, ${ }^{50}$ thus should be documented. Bae et al. ${ }^{50}$ found that among children with persistent residual deficits from PBPI "the upper arm, forearm, and hand lengths of the affected limbs were, on average, 95\%, 94\% and 97\% of the unaffected limb respectively". In a longitudinal study, Bain et al. ${ }^{51}$ collected measures of arm length and girth at regular time points until 12 months then yearly. The authors found that children with and without 
surgical intervention had significant differences between affected and unaffected sides with regard to arm, forearm, and total length as early as the 1-month time point. The 3-month total limb length difference was a statistically significant predictor of 12-month limb length difference. Although measurement of arm length and girth is not essential, since it is important for many parents/families, interlimb differences should be monitored.

\section{Sensorimotor Function and Prehension}

Children who sustain PBPI are at risk for temporary or long-lasting postural and developmental disorders ${ }^{52,87}$ Bellew et al. ${ }^{87}$ found a significant relationship between initial injury severity and level of development in young children who sustained PBPI. A change in hand preference based on capability post-injury could also influence motor learning and subsequent function. 87

Given the risk of disability, screening of sensorimotor development and prehensile function is recommended for the preschool child with PBPI. Currently, the Assisting Hand Assessment (AHA) ${ }^{63}$ is the only known prehensile assessment validated for use with PBPI. Table $2 \mathrm{~b}$ lists standardized measures that are potentially useful to assess prehension and sensorimotor skills of balance and visual-motor function that require validation for use after PBPI. Further research to validate these assessments for use with this population is warranted.

\section{Activity and Participation}

Children who sustain PBPI are at-risk for restrictions in activities and participation. ${ }^{105-106}$ Assessment of these aspects of the ICF framework are illustrated in the recently developed tool, The Brachial Plexus Outcome Measure (BPOM). ${ }^{59}$ The BPOM ${ }^{59}$ has two parts; the Activity Scale and the Self-Evaluation Scales designed to assess activity and participation in children who sustain PBPI (See Appendix D). The activity scale consists of eleven tasks, which contain components of the fifteen movements included in the AMS scale. ${ }^{20}$ Activity performance is graded using the Functional Movement Scale; an ordinal scale ranging from ' 1 ' cannot complete to ' 5 ' completes in a normal movement pattern symmetrical to the unaffected UE. The self-evaluation scale includes 3 visual analog scales $(100 \mathrm{~mm})$ to assess the perceived arm and hand function and cosmetic appearance of the limb. This tool has not yet undergone rigorous psychometric testing. Table $2 \mathrm{a}-\mathrm{b}$ lists other tools useful to assess activity and participation that have been validated, or are recommended for use pending validation, with this population.

A child's self-efficacy and self-esteem may be fragile due to the child's reaction or the reaction of others to their disability. Since these issues have the potential to limit participation in age-appropriate activities and sports they should be monitored. If needed, the child can be referred to a psychologist or social worker for additional support.

\section{Conclusions}

PBPI evident immediately after birth requires early assessment and follow-up with a team of PBPI specialists. Early assessment and care provides the infant with the best opportunity to 
improve sensory recognition, recover movement, prevent secondary musculoskeletal disorders, and integrate the arm into movement and age-appropriate activities. In addition to physical assessment, clinicians should be mindful of behavioral clues of psychological distress exhibited by the parents/caregivers or the infant/child. Education on the condition and home programs as well as referral to an appropriate professional can help to ease anxiety in these situations. Finally, the ICF model can guide the assessment process from infancy through adolescence. Attention to all facets of development can provide this vulnerable group of infants and children the best chance for recovery and life-long participation in areas of interest.

\section{Supplementary Material}

Refer to Web version on PubMed Central for supplementary material.

\section{Acknowledgements}

This work was supported by a grant from the Eunice Kennedy Shriver National Institute of Child Health and Human Development under award number T32 HD064578.

\section{References}

1. Hale HB, Bae DS, Waters PM. Current concepts in the management of brachial plexus birth palsy. $\mathrm{J}$ Hand Surg. 2010; 35A:322-331.

2. Dodds SD, Wolfe SW. Perinatal brachial plexus palsy. Curr Opin Pediatr. 2000; 12:40-47. [PubMed: 10676773]

3. Foad SL, Mehlman CT, Ying J. The epidemiology of neonatal brachial plexus palsy in the United States. J Bone Joint Surg Am. 2008; 90:1258-1264. [PubMed: 18519319]

4. Hoeksma AF, Wolf H, Oei SL. Obstetrical brachial plexus injuries: incidence, natural course and shoulder contracture. Clin Rehabil. 2000; 14(5):523-526. [PubMed: 11043878]

5. Hankins GD, Clark SL. Brachial plexus palsy involving the posterior shoulder at spontaneous vaginal delivery. Am J Perinatol. 1995; 12(1):44-45. [PubMed: 7710576]

6. Hansen A, Chauhan SP. Shoulder dystocia: definitions and incidence. Sem Perinatol. 2014; 38:184188.

7. Mehta H, Sokol RJ. Shoulder dystocia: Risk factors, predictability, and preventability. Sem Perinatol. 2014; 38:189-193.

8. Mollberg M, Hagberg H, Bager B, et al. High birthweight and shoulder dystocia: the strongest risk factors for obstetrical brachial plexus palsy in a Swedish population-based study. Acta Obstet Gynecol Scand. 2005; 84:654-659. [PubMed: 15954875]

9. Åberg K, Norman M, Ekéus C. Preterm birth by vacuum extraction and neonatal outcome: a population-based cohort study. BMC Pregnancy Childbirth. 2014; 14:42. [PubMed: 24450413]

10. Executive summary: neonatal brachial plexus palsy. Report of the American College of Obstetricians and Gynecologists' Task Force on Neonatal Brachial Plexus Palsy. Obstet Gynecol. 2014; 123(4):902-904. [PubMed: 24785634]

11. Ouzounian J. Risk factors for neonatal brachial plexus palsy. Sem Perinatol. 2014; 38:219-221.

12. Gurewitsch ED, Allen RH. Reducing the risk of shoulder dystocia and associated brachial plexus injury. Obstet Gynecol Clin N Am. 2011; 38:247-269.

13. Mollberg M, Lagerkvist AL, Johansson U, et al. Comparison in obstetric management on infants with transient and persistent obstetric brachial plexus palsy. J Child Neurol. 2008; 23(12):14241432. [PubMed: 19073848] 
14. Hoeksma AF, ter Steeg AM, Nelissen RG, et al. Neurological recovery in obstetric brachial plexus injuries: an historical cohort study. Dev Med Child Neurol. 2004; 46(2):76-83. [PubMed: 14974631]

15. Pondaag W, Malessy MJ, van Dijk JG, Thomeer RT. Natural history of obstetric brachial plexus palsy: a systematic review. Dev Med Child Neurol. 2004; 46:138-144. [PubMed: 14974639]

16. Strömbeck C, Krumlinde-Sundholm L, Remahl S, Forssberg H. Long-term follow-up of children with obstetric brachial plexus palsy I: functional aspects. Dev Med Child Neurol. 2007; 49:198203. [PubMed: 17355476]

17. Strömbeck C, Remahl S, Krumlinde-Sundholm L, Sejersen T. Long-term follow-up of children with obstetric brachial plexus palsy II: neurophysiological aspects. Dev Med Child Neurol. 2007; 49:204-209. [PubMed: 17355477]

18. Laurent JP, Lee R, Shenaq S, et al. Neurosurgical correction of upper brachial plexus birth injuries. J Neurosurg. 1993; 79:197-203. [PubMed: 8331400]

19. World Health Organization. [[cited 2014 Nov 08]] International Classification of Functioning, Disability and Health for Children and Youth (ICF-CY). 2014. Available from: http:// www.who.int/classifications/icf/en/

20. Clarke HM, Curtis CG. An approach to obstetrical brachial plexus injuries. Hand Clinics. 1995; 11(4):563-580. [PubMed: 8567739]

21. Curtis CG, Stephens D, Clarke HM, Andrews D. The active movement scale: an evaluative tool for infants with obstetrical brachial plexus palsy. J Hand Surg [Am]. 2002; 27(3):470-479.

22. Michelow BJ, Clarke HM, Curtis CG, et al. The natural history of obstetrical brachial plexus palsy. Plast Reconstr Surg. 1994; 93:675-681. [PubMed: 8134425]

23. Campbell, WW. DeJong's The Neurological Examination. 7th Ed.. Philadelphia: Lippincott Williams \& Wilkins; 2013.

24. Fiorentino, MR. Normal and Abnormal Development: the influence of Primitive Reflexes on Motor Development. Springfield, IL: Charles C. Thomas Pub; 1972.

25. Gabbard, CP. Early motor development. In: Gabbard, CP., editor. Lifelong Motor Development. San Francisco: Pearson Benjamin Cummings; 2012. p. 240-280.

26. Mallet J. Primaute du traitement de l'epaule -- methode d'expresion des resultats. Rev Chir Orthop. 1972; 58S:166-168. [PubMed: 4263979]

27. Abzug JM, Kozin SH. Evaluation and management of brachial plexus birth palsy. Orthop Clin N Am. 2014; 45:225-232.

28. James MA. Use of the Medical Research Council muscle strength grading system in the upper extremity. J Hand Surg. 2007; 32(2):154-156.

29. Ho E. Evaluation of pediatric upper extremity peripheral nerve injuries. J Hand Ther. 2015

30. Narakas, AO. Obstetrical brachial plexus injuries. In: Lamb, DW., editor. The Paralyzed Hand. New York: Churchill Livingstone; 1987. p. 116-135.

31. Al-Qattan MM, El-Sayed AAF, Al-Zahrani AY, et al. Narakas classification of obstetric brachial plexus palsy revisited. J Hand Surg [Eur]. 2009; 34:788-791.

32. Birch, R.; Bonney, G.; Wynn Parry, CB. Birth Lesions of the Brachial Plexus. Surgical Disorders of the Peripheral Nerves. London: Churchill Livingstone; 1998. p. 209-233.

33. Gilbert, A.; Raimondi, P. International meeting on obstetric brachial plexus palsy. Heerlen, NL; 1996. Evaluation of results in obstetric brachial plexus palsy. The elbow; p. 24

34. Al-Qattan M. Assessment of the motor power in older children with obstetric brachial plexus palsy. J Hand Surg [Br]. 2003; 28(1):46-49.

35. Raimondi, P. International meeting on obstetric brachial plexus palsy. Heerlen, NL: 1993. Evaluation of results in obstetric brachial plexus palsy. The hand.

36. VanderHave KL, Bovid K, Alpert H, et al. Utility of electrodiagnostic testing and CT myelography in the preoperative evaluation of neonatal brachial plexus birth palsy. J Neurosurg Pediatr. 2012; 9(3):283-289. [PubMed: 22380957]

37. Heise CO, Siqueira MG, Martins RS, Gherpelli JL. Clinical-electromyography correlation in infants with obstetric brachial plexopathy. J Hand Surg Am. 2007; 32:999-1004. [PubMed: 17826552] 
38. Van Dijk JG, Pondaag W, Malessy MJA. Obstetric lesions of the brachial plexus. Muscle Nerve. 2001; 24:1451-1461. [PubMed: 11745946]

39. Vredeveld JW, Blaauw G, Slooff BA, et al. The findings in paediatric obstetric brachial palsy differ from those in older patients: a suggested explanation. Dev Med Child Neurol. 2000; 42:158161. [PubMed: 10755454]

40. van Dijk JG, Pondaag W, Buitenhuis SM, et al. Needle electromyography at 1 month predicts paralysis of elbow flexion at 3 months in obstetric brachial plexus lesions. Dev Med Child Neurol. 2012; 54:753-758. [PubMed: 22671144]

41. Duff SV, Levy TJ, Zelonis S, Hassink A, Kimbel A, Kushner R, Smith SA, Finkel R, Gabriel D. Early identification of upper limb asymmetry in infants at-risk. Poster. Research Day Division of Biokinesiology and Physical Therapy, University of Southern CA. 2013 Apr.

42. Somashekar D, Yang LJ, Ibrahim M, Parmar HA. High-resolution MRI evaluation of neonatal brachial plexus promising alternative to traditional CT myelography. Am J Neuroradiol. 2014; 35:1209-1213. [PubMed: 24356673]

43. Chin KF, Misra VP, Sicuri GM, et al. Intra-operative neurophysiological prediction of upper trunk recovery in obstetric brachial plexus palsy with neuroma in continuity. Bone Joint J. 2013; 95B(5):699-705. [PubMed: 23632685]

44. Yang J-S. Neonatal brachial plexus palsy-Management and prognostic factors. Sem Perinatal. 2014; 38:222-234.

45. Joseph JR, DiPietro MA, Somashekar D, Parmar HA, Yang LJ. Ultrasonography for neonatal brachial plexus palsy. J Neurosurg Pediatr. 2014; 14(5):527-531. [PubMed: 25216291]

46. Kozin SH, Zlotolow DA. Advanced imaging and arthroscopic management of shoulder contractures after birth palsy. Hand Clin. 2012; 28(4) 541-50.47.

47. Gharbaoui IS, Gogola GR, Aaron DH, Kozin SH. Relationship between glenohumeral joint contractures and shoulder dysfunction range in children with perinatal brachial plexus birth palsy. J Hand Ther. 2015

48. Russo SA, Kozin SH, Zlotolow DA, et al. Scapulothoracic and glenohumeral contributions to motion in children with brachial plexus birth palsy. J Shoulder Elbow Surg. 2014; 23:327-338. [PubMed: 24075782]

49. Duff SV, Dayanidhi S, Kozin SH. Asymmetrical shoulder kinematics in children with brachial plexus birth palsy. Clin Biomech. 2007; 22(6):630-638.

50. Bae DS, Ferretti M, Waters PM. Upper extremity size differences in brachial plexus birth palsy. Hand. 2008; 3:297. 303. [PubMed: 18780022]

51. Bain JR, DeMatteo C, Gjertsen D, et al. Limb length differences after obstetrical brachial plexus injury: a growing concern. Plast Reconstr Surg. 2012; 130(4):558e-571e.

52. Ridgway E, Valicenti-McDermott M, et al. Effects from birth brachial plexus injury and postural control. J Pediatr. 2013; 162(5):1065-1067. [PubMed: 23394776]

53. Merkel S, Voepel-Lewis T, Malviya S. Pain assessment in infants and young children: FLACC scale. Am J Nurse. 2002; 102(10):55-58.

54. Garra G, Singer AJ, Taira BR, et al. Validation of the Wong-Baker FACES Pain Rating Scale in Pediatric Emergency Department Patients. Acad Emerg Med. 2010; 17(1):50-54. [PubMed: 20003121]

55. O'Riain S. New and simple test of nerve function in hand. Br Med J. 1973; 3(5881):615-616. [PubMed: 4755183]

56. Menier C, Forget R, Lambert J. Evaluation of two-point discrimination in children: reliability effects of passive displacement and voluntary movements. Dev Med Child Neurol. 1996; 38(6): 523-537. [PubMed: 8647332]

57. Tajima T, Imai H. Results of median nerve repair in children. Microsurg. 1989; 10(2):145-146.

58. Mulcahey MJ, Merenda L, Tian F, Kozin S, James M, Gogola G, Ni P. Computer adaptive test approach to the assessment of children and youth with brachial plexus birth palsy. Am J Occup Ther. 2013; 67(5):524-533. [PubMed: 23968790]

59. Ho ES, Curtis CG, Clarke HM. The Brachial Plexus Outcome Measure: development, internal consistency, and construct validity. J Hand Ther. 2012; 25(4):406-417. [PubMed: 22818900] 
60. Haley, SM. Pediatric Evaluation of Disability Inventory (PEDI): Development, standardization and administration manual. PEDI Research Group; 1992.

61. Ho ES, Curtis CG, Clarke HM. Pediatric Evaluation of Disability Inventory: its application to children with obstetric brachial plexus palsy. J Hand Surg Am. 2006; 31(2):197-202. [PubMed: 16473678]

62. Haley SM, Coster WJ, Dumas HM, et al. Accuracy and precision of the Pediatric Evaluation of Disability Inventory computer-adaptive tests (PEDI-CAT). Dev Med Child Neurol. 2013; 38(12): 2426-2431.

63. Holmefur M, Krumlinde-Sundholm L, Eliasson AC. Interrater and intrarater reliability of the assisting hand assessment. Am J Occup Ther. 2007; 61:79-84. [PubMed: 17302108]

64. Mahan ST, Kalish LA, Connell PL, Harris M, Abdul-Rahim Z, Waters P. PedsQL correlates to PODCI in pediatric orthopaedic outpatient clinic. J Pediatr Orthop. 2014; 34(6):e22-e26. [PubMed: 25275143]

65. Huffman GR, Bagley AM, James MA, et al. Assessment of children with brachial plexus birth palsy using the Pediatric Outcomes Data Collection Instrument. J Pediatr Orthop Am. 2005; 25:400-404.

66. Brazelton, TB.; Nugent, JK. Neonatal Behavioral Assessment Scale. London: MacKeith Press; 2001.

67. Bouwstra H, Dijk-Stigter GR, Grooten HMJ, et al. Predictive value of definitely abnormal general movements in the general population. Dev Med Child Neurol. 2010; 52(5):456-461. [PubMed: $20002118]$

68. Buitenhuis S, van Wijlen-Hempel RS, Pondaag W, Malessy MJA. Obstetric brachial plexus lesions and central developmental disability. Early Hum Develop. 2012; 88:731-734.

69. Campbell S. Test-retest reliability of the Test of Infant Motor Performance. Pediatr Phys Ther. 1999; 11:60-66.

70. Piper, MC.; Darrah, J. Motor Assessment of the Developing Infant. Phila: WB Saunders; 1994.

71. Folio MR, Fewell RR. Peabody Developmental Motor Scales (2nd Ed.). 1974

72. Bayley, N. Bayley Scales of Infant and Toddler Development: Bayley-III. Harcourt Assessment, Psych. Corp; 2006.

73. Gogola GR, Velleman PF, Zu S, Morse AM, Lacy B, Aaron D. Hand dexterity in children: administration and normative values of the functional dexterity test. J Hand Surg Am. 2013; 38(12):2426-2431. [PubMed: 24183507]

74. Poole JL, Burtner PA, Torres TA, et al. Measuring Dexterity in Children Using the Nine-hole Peg Test. J Hand Ther. 2005; 18:348-351. [PubMed: 16059856]

75. Bruininks, RH.; Bruininks, BD. BOT2: Bruininks-Oseretsky Test of Motor Proficiency: Administration Easel. Pearson Assessments; 2005.

76. Miller, LJ. Miller Assessment for Preschoolers (MAP). San Antonio: Psychologic Corporation; 1988-Revision.

77. Bourke-Taylor H. Melbourne assessment of unilateral upper limb function: construct validity and correlation with the pediatric evaluation of disability inventory. Dev Med Child Neurol. 2003; 45(2):92-96. [PubMed: 12578234]

78. Henderson, SE.; Sugden, DA.; Barnett, AL. Movement Assessment Battery for Children-2: Movement ABC-2: Examiner's Manual. Pearson; 2007.

79. DeMatteo C, Law M, Russell D, et al. The reliability and validity of the Quality of Upper Extremity Skills Test. Phys Occup Ther Ped. 1993; 13(2):1-18.

80. Ravens-Sieberer U, Gosc A, Rajmil L, et al. The KIDSCREEN-52 Quality of Life Measure for Children and Adolescents: Psychometric Results from a Cross-Cultural Survey in 13 European Countries. Value Health. 2008; 11(4):645-658. [PubMed: 18179669]

81. McColl MA, Paterson M, Davies D, Doubt L, Law M. Validity and community utility of the Canadian Occupational Performance Measure. Can J Occup Ther. 2000; 67(1):22-30. [PubMed: 10695166]

82. Turner-Stokes L. Goal attainment scaling (GAS) in rehabilitation: a practical guide. Clin Rehabil. 2009; 23:362-370. [PubMed: 19179355] 
83. Keller J, Kafkes A, Kielhofner G. Psychometric Characteristics of the Child Occupational SelfAssessment (COSA), part one: an initial examination of psychometric properties. Scand J Occup Ther. 2005; 12(3):118-127. [PubMed: 16389737]

84. Miller, LJ. Miller Function \& Participation Scales: Manual. PsychCorp; 2006.

85. DeMatteo C, Bain JR, Gjertsen D, Harper JA. 'Wondering and waiting' after obstetrical brachial plexus injury: Are we underestimating the effects of the traumatic experience on the families? Can J Plast Surg. 2014; 22(3):183-187. [PubMed: 25332647]

86. Brazelton, TB.; Cramer, BG. The earliest relationship: Parents, infants and the drama of early attachment. London: Karnac Books; 2002.

87. Bellew M, Kay SPJ, Webb F, Ward A. Developmental and behavioural outcome in obstetric brachial plexus palsy. J Hand Surg [Br Eur Vol]. 2000; 25B(10):49-51.

88. Yang LJS, Anand P, Birch R. Limb preference in children with obstetric brachial plexus palsy. Ped Neurol. 2005; 33(1):46-49.

89. Kaplan SL, Coulter C, Fetters L. Physical therapy management of congenital muscular torticollis: an evidence-based clinical practice guideline. Ped Phys Ther. 2013; 25(4):348-394.

90. Kuo AA, Tritasavit S, Graham JM. Congenital muscular torticollis and positional plagiocephally. Pediatr Rev. 2014; 35(2):79-87. [PubMed: 24488831]

91. Gosk J, Koszewica M, Urban M, et al. Assessment of the prognostic value of horner syndrome in perinatal brachial plexus palsy. Neuropediatrics. 2011; 42(1):4-6. [PubMed: 21557143]

92. Karabiber H, Ozkan KU, Garipardic M, Parmaksiz G. An overlooked association of brachial plexus palsy: diaphragmatic paralysis. Acta Paediatr Taiwan. 2004; 45(5):301-303. [PubMed: 15868816]

93. Dharmar M, Romano PS, Kuppermann N, et al. Impact of critical care telemedicine consultations on children in rural emergency departments. Crit Care Med. 2013; 41(10):2388-2395. [PubMed: 23921273]

94. Alsubhi FS, Althunyan AM, Curtis CG, Clarke HM. Radial nerve palsy in the newborn: a case series. CMAJ. 2011; 183(12):1367-1370. [PubMed: 21768251]

95. Monica JT, Waters PM, Bae DS. Radial nerve palsy in the newborn: a report of four cases and literature review. J Pediatr Orthop. 2008; 28(4):460-462. [PubMed: 18520284]

96. Nicholson L. Cephalohematoma: The Cs that leave bumps on the head. Neonatal Netw. 2007; 26(5):277-281. [PubMed: 17926657]

97. Einspieler, C.; Prechtl, HF.; Bos, AF.; Ferrari, F.; Cioni, G. Prechtl's method on the qualitative assessment of general movements in preterm, term and young infants. London: MacKeith Press, Cambridge University Press; 2004.

98. Hadders-Algra M, Mavinkurve-Groothuis AM, Groen SE, et al. Quality of general movements and the development of minor neurological dysfunction at toddler and school age. Clin Rehabil. 2004; 18:287-299. [PubMed: 15137560]

99. Bialocerkowski AE, Galea M. Comparison of visual and objective quantification of elbow and shoulder movement in children with obstetric brachial plexus palsy. J Brachial Plex Peripher Nerve Inj. 2006; 1(5)

100. Alyanak B, Kilincaslan A, Kutlu L, et al. Psychological adjustment, maternal distress, and family functioning in children with obstetrical brachial plexus palsy. J Hand Surg. 2013; 38A:137-142.

101. McLean LA, Harvey D, Mutimer K. Risk and resistance factors associated with parental adjustment to Obstetrical Brachial Plexus Injuries. J Clin Psychol Med Settings. 2014; 21:244. 252. [PubMed: 25038749]

102. Al-Qattan MM. Self-mutilation in children with obstetric brachial plexus palsy. J Hand Surg Br. 1999; 24(5):547-549. [PubMed: 10597929]

103. McCann ME, Waters P, Goumnerova LC, Berde C. Self-mutilation in young children following brachial plexus birth injury. Pain. 2004; 110(1-2):123-129. [PubMed: 15275759]

104. Kozin SH, Chafetz RS, Shaffer A, et al. Magnetic resonance imaging and clinical findings before and after tendon transfers about the shoulder in children with residual brachial plexus palsy: a 3year follow-up study. J Pediatr Orthop. 2010; 30(2):154-160. [PubMed: 20179563] 
105. Bae DS, Waters PM, Zurakowski D. Correlation of pediatric outcomes data collection instrument with measures of active movement in children with brachial plexus birth palsy. J Pediatr Orthop. 2008; 28(5):584-592. [PubMed: 18580377]

106. Spaargaern E, Ahmed J, van Ouwerkerk WJ, et al. Aspects of activities and participation of 7-8 year-old children with obstetric brachial plexus injury. Eur J Paediatr Neurol. 2011; 15(4):345352. [PubMed: 21511503]

107. Bain JR, DeMatteo C, Gjertsen D, Hollenberg RD. Navigating the gray zone: a guideline for surgical decision making in obstetrical brachial plexus injuries. J Neurosurg Pediatr. 2009; 3(3): 173-180. [PubMed: 19338462]

108. DeMatteo C, Bain JR, Galea V, Gjertsen D. Botulinum toxin as an adjunct to motor learning therapy and surgery for obstetrical brachial plexus injury. Dev Med Child Neurol. 2006; 48:245252. [PubMed: 16542510] 


\section{Highlights}

ICF guides assessment after perinatal brachial plexus injury

Use of sensitive measures is essential 


\section{Health Condition}

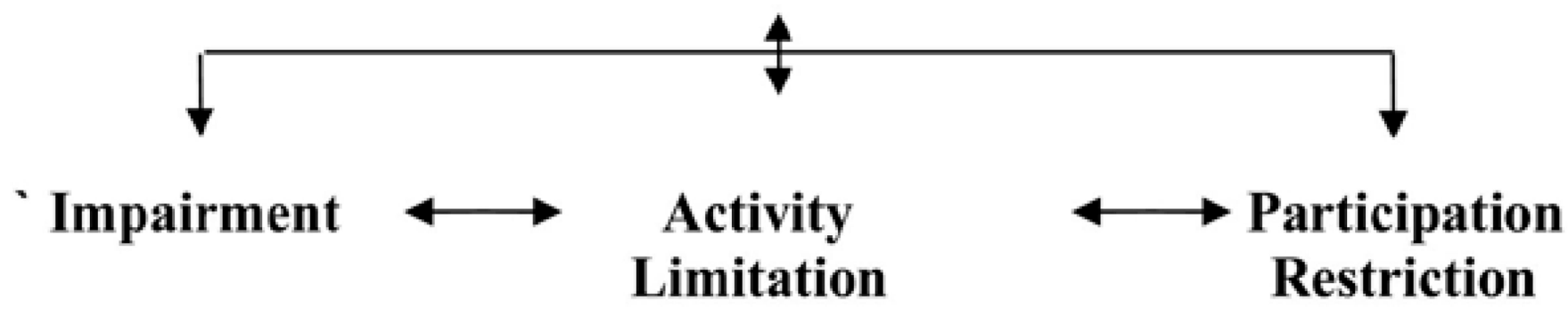

个

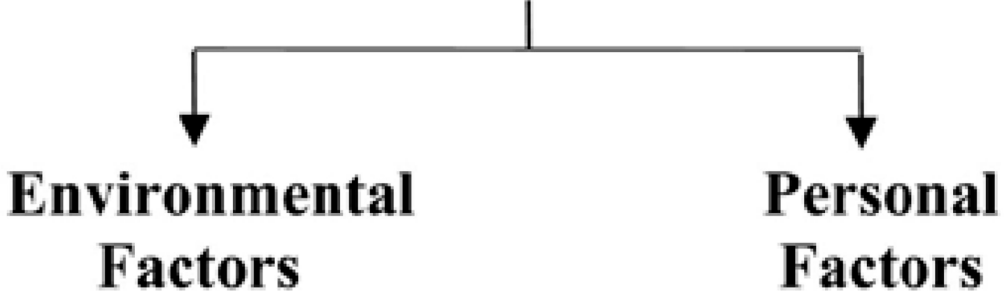

Fig. 1.

International Classification of Functioning, Disability, and Health 


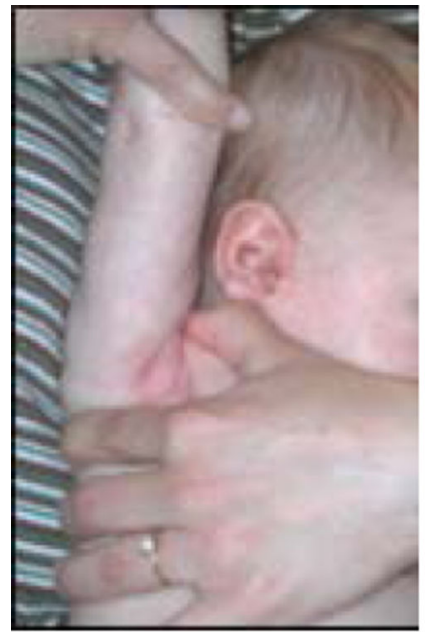

A

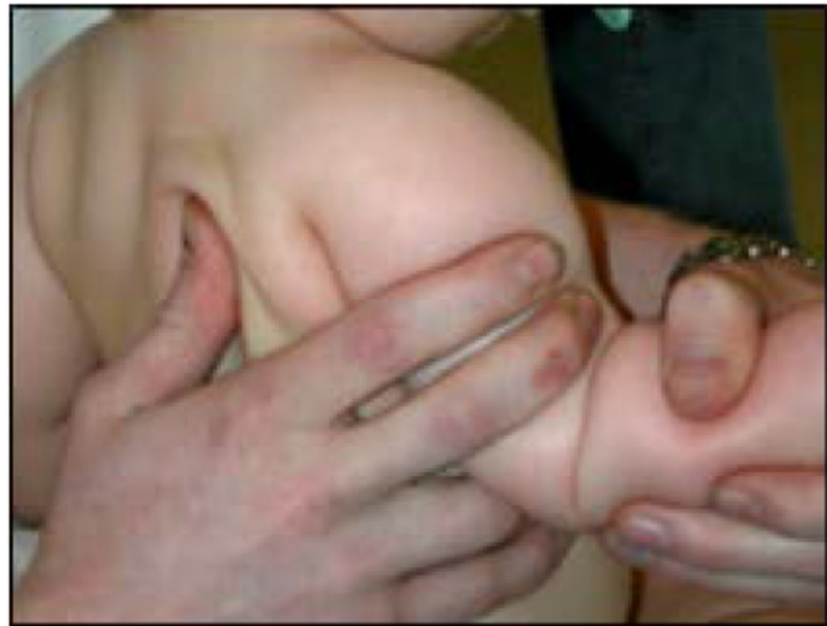

B

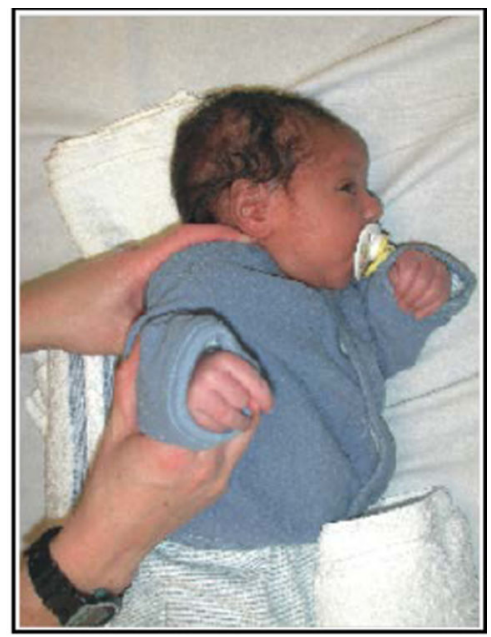

C

Fig. 2.

Scapular stabilization: A) lateral during humeral elevation; B) medial and superior during humeral external rotation; C) PROM into external rotation in the sidelying position. (courtesy of SV Duff). 


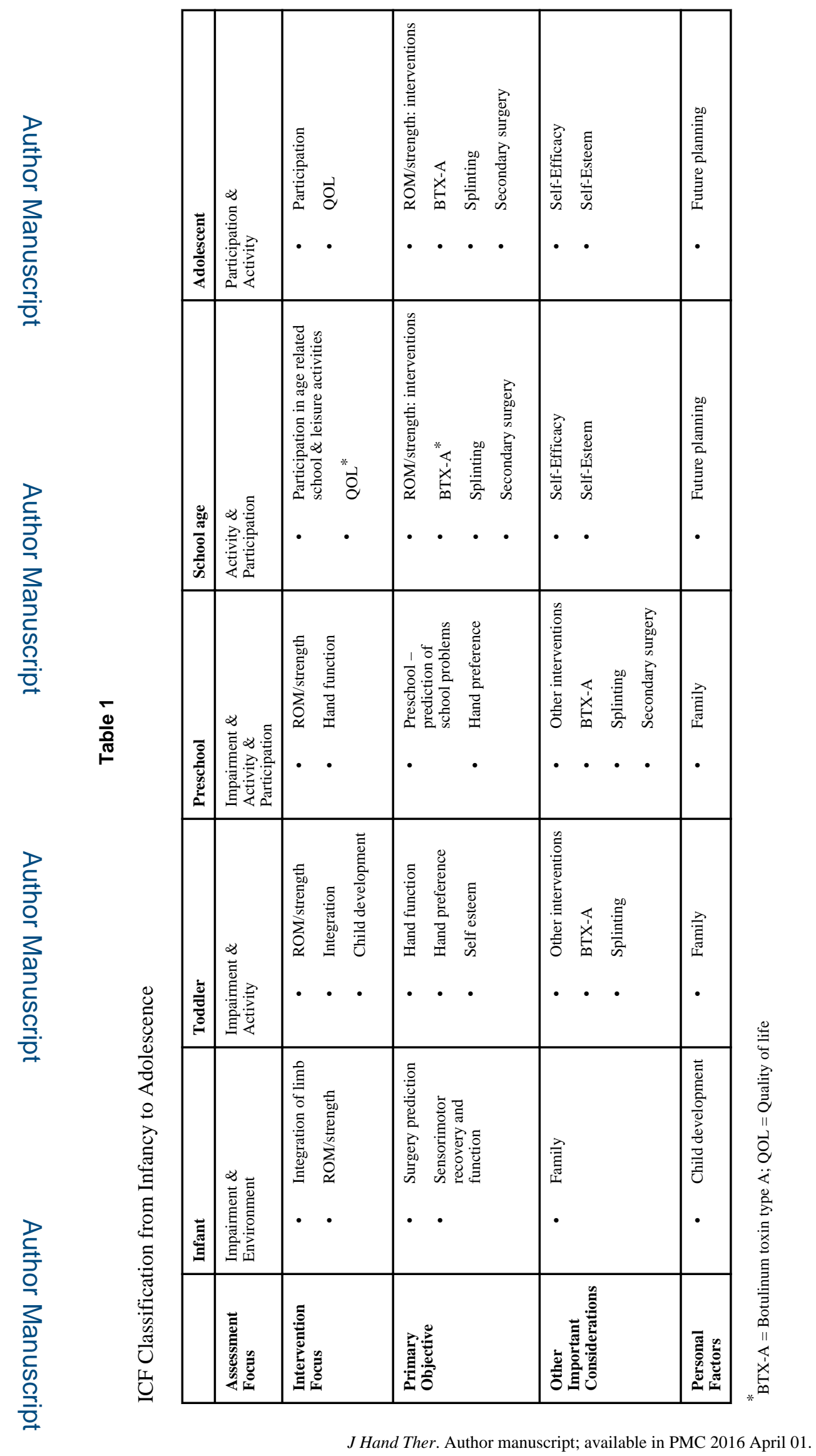


Table 2

\begin{tabular}{|c|c|c|}
\hline \multicolumn{3}{|c|}{ a: Outcome Measures Validated with PBPI - ICF Classification } \\
\hline $\begin{array}{l}\text { BODY FUNCTIONS \& STRUCTURES } \\
\text { Impairment }\end{array}$ & $\begin{array}{l}\text { ACTIVITY } \\
\text { Limitation }\end{array}$ & $\begin{array}{l}\text { PARTICIPATION } \\
\text { Restriction }\end{array}$ \\
\hline $\begin{array}{ll}\text { ACTIVE } & \text { MOTION/STRENGTH } \\
\text { - } & \text { AMS }^{20-21} \\
\text { - } & \text { Toronto Test } \\
\text { - } & \text { Primitive Reflexes / Postural Reactions }^{23-25} \\
\text { - } & \text { Mallet }^{26} \& \text { Modified Mallet Shoulder Scale } \\
\text { - } & \text { MRC scale } \\
\text { - } & \text { Pinch/grip dynamometery }{ }^{29}\end{array}$ & $\begin{array}{l}\text { FUNCTIONAL } \\
\begin{aligned} \text { - } & \text { BP Activity and UE CAT }{ }^{58} \\
\text { - } & \text { BPOM }^{59} \\
\text { - } & \text { PEDI }{ }^{60-61} \text { PEDI-CAT }^{62}\end{aligned}\end{array}$ & $\begin{array}{r}\text { QUALITY OF LIFE } \\
\text { • } \quad \text { Peds-QL }{ }^{64}\end{array}$ \\
\hline 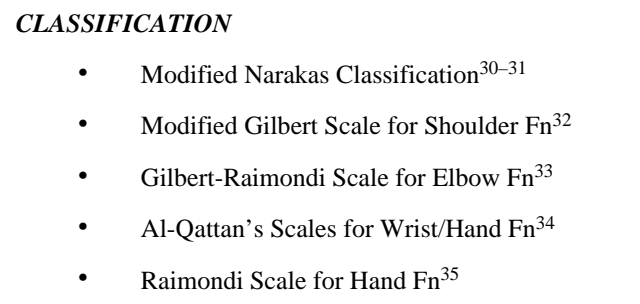 & $\begin{array}{r}\text { UNI-BIMANUAL } \\
\text { - } \quad \mathrm{AHA}^{63}\end{array}$ & $\begin{array}{cc}\text { PARTICIPATION } \\
\text { • } \\
\text { BPOM } \\
\text { - } & \text { PODCI }^{65}\end{array}$ \\
\hline $\begin{array}{l}\text { DIAGNOSTICS } \\
\begin{array}{ll}\text { - } & \text { CT Myelogram },{ }^{36} \mathrm{EMG}^{37-41} \mathrm{MRI},{ }^{42} \mathrm{NCS}^{43-44} \\
\text { - } & \text { Ultrasound }{ }^{45-46}\end{array}\end{array}$ & & \\
\hline $\begin{aligned} & \text { NEUROLOGICAL } \\
& \text { - } \\
& \text { - } \text { Deep Tendon Reflexes }{ }^{23} \\
& \text { - } \text { Muscle Tone }{ }^{23} \\
& \text { Primitive Reflexes / Postural Reactions }{ }^{23-25}\end{aligned}$ & & \\
\hline $\begin{array}{ll}\text { PHYSICAL } & \\
\text { - } & \text { Gleno/scapular angles }{ }^{47} \\
\text { - } & \text { Kinematic assessment }{ }^{48-49} \\
\text { - } & \text { Limb length/girth } \\
\text { - } & \text { Postural assessment } \\
& 52 \\
\text { - } & \text { PROM }^{28}\end{array}$ & & \\
\hline 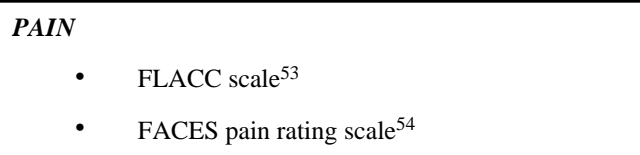 & & \\
\hline $\begin{array}{ll}\text { SENSATION } \\
\begin{array}{ll}\text { - } & \text { Sensory Grading System Narakas } \\
\text { - } & \text { Wrinkle test } \\
& 55 \\
\text { - } & \text { Two-point discrimination } \\
56\end{array}\end{array}$ & & \\
\hline
\end{tabular}




\begin{tabular}{|l|l|l|}
\hline a: Outcome Measures Validated with PBPI - ICF Classification & \multicolumn{2}{|l|}{$\begin{array}{l}\text { PARTICIPATION } \\
\text { Restriction }\end{array}$} \\
\hline $\begin{array}{l}\text { BODY FUNCTIONS \& STRUCTURES } \\
\text { Impairment }\end{array}$ & $\begin{array}{l}\text { ACTIVITY } \\
\text { Limitation }\end{array}$ \\
\hline$\quad$ Semmes Weinstein Monofilaments & \\
\hline
\end{tabular}

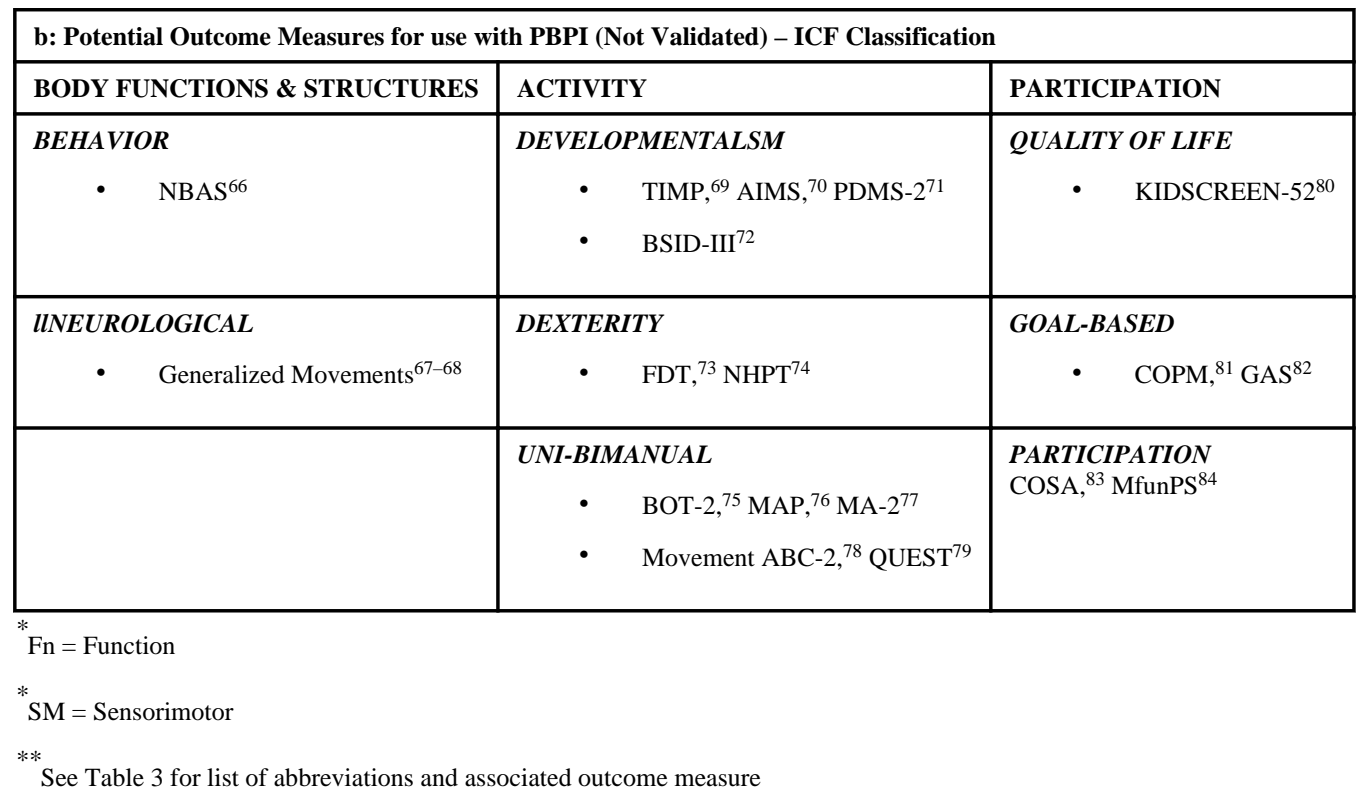


Table 3

Outcome Measure Abbreviations

\begin{tabular}{|c|c|}
\hline ABBREVIATION & OUTCOME MEASURE \\
\hline AIMS & Alberta Infant Motor Scale \\
\hline AHA & Assisting Hand Assessment \\
\hline AMS & Active Movement Scale \\
\hline ВPOM & Brachial Plexus Outcome Measure \\
\hline BOT-2 & Bruininks-Oseretsky Test of Motor Proficiency, $2^{\text {nd }} E d$ \\
\hline BSID III & Bayley Scales of Infant Development, $3^{\text {rd }} \mathrm{Ed}$ \\
\hline BP Activity and UE CAT & Brachial Plexus Activity and Upper Extremity Computerized Adaptive Testing \\
\hline COPM & Canadian Occupational Performance Measure \\
\hline COSA & Child Occupational Self-Assessment \\
\hline $\mathrm{CT}$ & Computed Tomography \\
\hline EMG & Electromyography \\
\hline FLACC & Face, Legs, Activity, Cry, Consolability Scale \\
\hline FDT & Functional Dexterity Test \\
\hline GAS & Goal Attainment Scaling \\
\hline GMs & Generalized Movements \\
\hline MA-2 & Melbourne Assessment 2 \\
\hline MAP & Miler Assessment of Preschoolers \\
\hline MfunPS & Miller Function and Participation Scales \\
\hline Movement ABC-2 & Movement Assessment Battery for Children-2 $2^{\text {nd }} \mathrm{Ed}$ \\
\hline MRC & Medical Research Council \\
\hline MRI & Magnetic Resonance Imaging \\
\hline NBAS & Neonatal Behavioral Assessment Scale \\
\hline NCS & Nerve Conduction Studies \\
\hline NHPT & Nine Hole Peg Test \\
\hline QUEST & Quality of Upper Extremity Skills Test \\
\hline PDMS-2 & Peabody Developmental Motor Scales, ${ }^{2 \text { nd }}$ Ed \\
\hline PEDI-CAT & Pediatric Evaluation of Disability Inventory - Computer Adapted Testing \\
\hline Peds QL & Pediatric Quality of Life \\
\hline PODCI & Pediatric Outcomes Data Collection Instrument \\
\hline QUEST & Quality of Upper Extremity Skills Test \\
\hline PROM & Passive Range-of-Motion \\
\hline TIMP & Test of Infant Motor Performance \\
\hline
\end{tabular}

J Hand Ther. Author manuscript; available in PMC 2016 April 01. 


\section{Table 4}

The FLACC Scale to Assess Non-Verbal Signs of Pain

\begin{tabular}{|l|l|l|l|}
\hline CRITERIA & Score 0 & Score 1 & Score 2 \\
\hline Face & No particular expression or smile & $\begin{array}{l}\text { Occasional grimace or frown, withdrawn, } \\
\text { uninterested }\end{array}$ & $\begin{array}{l}\text { Frequent to constant quivering } \\
\text { chin, clenched jaw }\end{array}$ \\
\hline Legs & Normal position or relaxed & Uneasy, restless, tense & Kicking, or legs drawn up \\
\hline Activity & $\begin{array}{l}\text { Lying quietly, normal position } \\
\text { moves easily }\end{array}$ & Squirming, shifting, back and forth, tense & Arched, rigid or jerking \\
\hline Cry & No cry (awake or asleep) & Moans or whimpers; occasional complaint & $\begin{array}{l}\text { Crying steadily, screams or sobs, } \\
\text { frequent complaints }\end{array}$ \\
\hline Consolability & Content, relaxed & $\begin{array}{l}\text { Reassured by occasional touching, hugging or } \\
\text { being talked to, distractible }\end{array}$ & Difficult to console or comfort \\
\hline
\end{tabular}

Merkel S, Voepel-Lewis T, Malviya S. Pain assessment in infants and young children: the FLACC scale. Am J Nurse. 2002;102(10)55-8. 


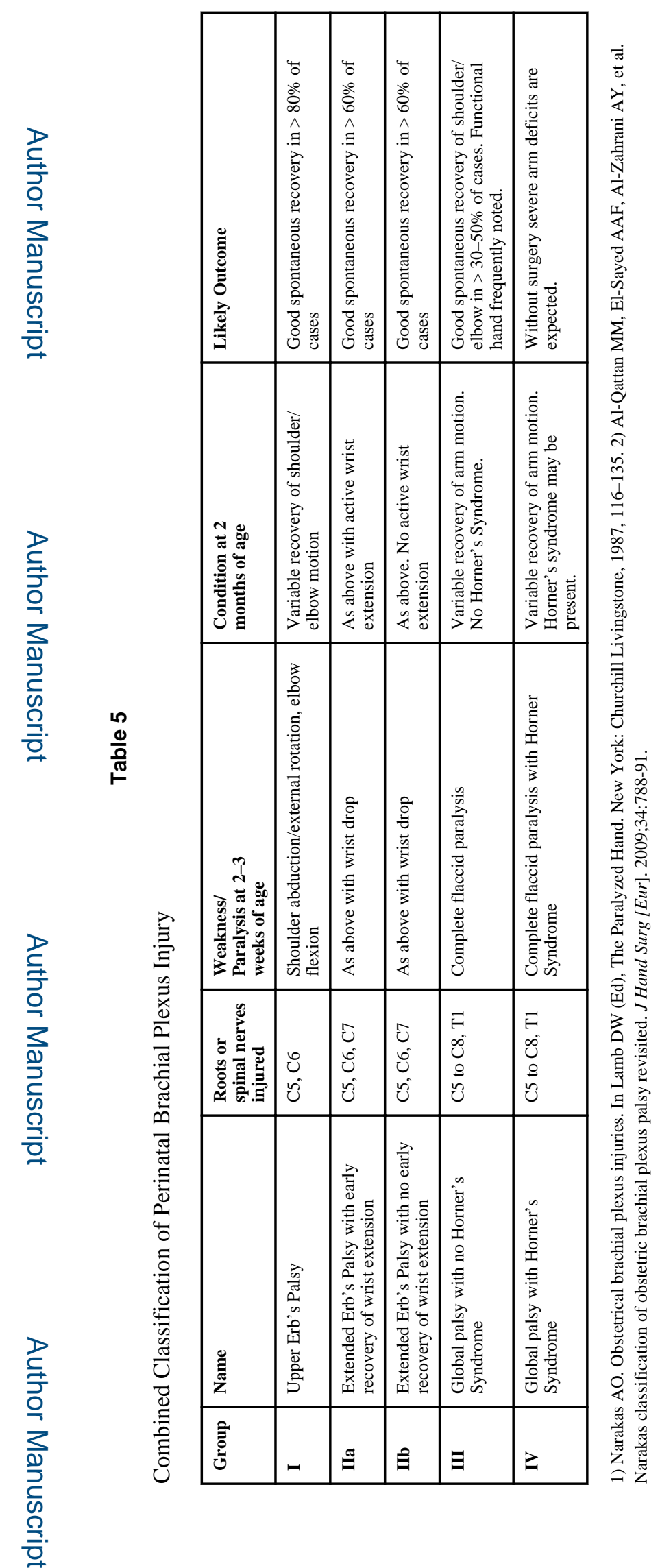

J Hand Ther. Author manuscript; available in PMC 2016 April 01. 
Table 6

Key Primitive Reflexes Elicited to Assess Muscle Activation after PBPI

\begin{tabular}{|l|l|l|l|}
\hline NAME & AGE & STIMULUS & RESPONSE \\
\hline Moro Reflex & $0-4$ months & Sudden neck extension into gravity & $\begin{array}{l}\text { Shoulder abduction/external } \\
\text { rotation and elbow flexion }\end{array}$ \\
\hline Placing Reaction & $0-6$ months & $\begin{array}{l}\text { Tactile stimulation along dorsum of } \\
\text { hand at the edge of a table }\end{array}$ & $\begin{array}{l}\text { Shoulder flexion with wrist } \\
\text { extension }\end{array}$ \\
\hline Grasp Reflex & $0-4$ months & Pressure in palm of hand & Flexion of the fingers \\
\hline $\begin{array}{l}\text { Asymmetrical Tonic Neck Reflex } \\
\text { (ATNR) }\end{array}$ & 6 weeks to 6 months & Head turning toward one side & $\begin{array}{l}\text { Elbow extension on face side; } \\
\text { elbow flexion on skull side }\end{array}$ \\
\hline Forward Protective Response & Onset 6-7 months & $\begin{array}{l}\text { Hold infant securely at chest, move } \\
\text { infant forward toward surface in head- } \\
\text { first positions }\end{array}$ & $\begin{array}{l}\text { Arm extension and abduction } \\
\text { bilaterally }\end{array}$ \\
\hline Sideward Protective Response & Onset 6-11 months & $\begin{array}{l}\text { With infant in sitting gently move } \\
\text { laterally to elicit protective response }\end{array}$ & $\begin{array}{l}\text { Arm extension or abduction to the } \\
\text { side to prevent falling }\end{array}$ \\
\hline
\end{tabular}

1) Fiorentino MR. Normal and Abnormal Development: the influence of Primitive Reflexes on Motor Development. Springfield, IL: Charles C. Thomas Pub. 1972. 2) Gabbard CP. Early motor development. In Gabbard CP (Ed) Lifelong Motor Development. San Francisco: Pearson Benjamin Cummings, 2012, pp. 240-280. 


\section{Table 7}

\section{Sensory Grading System}

\begin{tabular}{|l|l|}
\hline S0 & No reaction to painful stimuli or any other stimuli \\
\hline S1 & Reaction to painful stimuli, none to touch \\
\hline S2 & Reaction to touch, but not light touch \\
\hline S3 & Apparently normal sensation \\
\hline
\end{tabular}

1) Narakas AO. Obstetrical brachial plexus injuries. In Lamb DW (Ed), The Paralyzed Hand. New York: Churchill Livingstone, 1987, 116-135. 2) Al-Qattan MM, El-Sayed AAF, Al-Zahrani AY, Al-Mutairi AS, Al-Harbi MS, Al-Mutairi AM, Al-Kahtani FS. Narakas classification of obstetric brachial plexus palsy revisited. J Hand Surg [Eur]. 2009;34:788-91. 